\title{
General Editorial on Publication Ethics
}

The scientific research and publishing communities the world over are by now well aware that over the past few decades, instances of scientific misconduct seem to be on the rise. These are consequences of the increasing pressures to publish for career advancement, competition for research support, and desire for recognition, influence and fame. In recent years many editorials have been written and international conferences have been held to discuss this issue which seriously affects both the conduct of science and the public perception of science.

The major forms of scientific misconduct are captured by three words: fabrication, falsification and plagiarism. Their meanings are self-evident. The first two forms are most likely to be detected by the rigorous peer review process instituted by all professional journals of quality. In those cases where a mendacious piece of work escapes detection and gets published, we can hope that later work by other scientists will expose the original misconduct.

We are concerned here particularly with plagiarism, which has become easier thanks to the growth of the Internet and easy access to vast amounts of written material. One dictionary defines plagiarism as "the appropriation or imitation of the language, ideas, and thoughts of another author, and representation of them as one's original work".

The degree of plagiarism could be as mild as the copying of a single sentence from another author without acknowledgement, or could involve much more extensive 'lifting of material' from other sources, including previous publications of the author. John Ziman has emphasized that the three forms of misconduct mentioned above are equally serious and reprehensible: "plagiarism is as infamous as fabrication in a scientific paper". As reprehensible as appropriating the thoughts, wording or visual representation from the work of someone else is 'self-plagiarism', which is the reproduction without acknowledgement of one's own earlier published work, in whole or in part, under the guise of something original.

The Indian Academy of Sciences takes a very serious view of all forms of scientific misconduct, and especially of plagiarism (including self-plagiarism), as something directly affecting the integrity of the scientific process. Such behaviour is unacceptable and deserves exposure and an appropriate level of penalty. In case it is inadvertently published, a paper containing plagiarised material steals credit from the original source and erodes confidence in the quality and reliability of our journals.

To counter these problems, we have instituted several measures uniformly for all Academy journals. Every case of suspected plagiarism brought to our attention will be investigated objectively and transparently by the journal editors as speedily as possible. If plagiarism is detected during the refereeing process, apart from immediate rejection the Academy will consider other steps commensurate with the seriousness of the case. In those situations where plagiarism is proven after publication, appropriate announcements will be placed, both online and in the next possible print issue of the journal.

The Academy reserves the right to bring such instances to the attention of the author's employers and funding agencies, and also to inform the original author (where applicable) whose work has been plagiarized and the journal from where the plagiarised material has been taken.

We join our readers and contributors in continuing to hope that the vigilance and care exercised by our referees and editors will minimise this problem.

\section{R Ramaswamy \\ Editor of Publications}

\section{N Mukunda}

Previous Editor of Publications

\section{S S Krishnamurthy}

Editor

Journal of Chemical Sciences

Dated January 2013 